duction. Finally, the secretion of intrinsic factor also precedes that of pepsin.

\section{Summary}

The secretion of gastric intrinsic factor was studied in normal subjects and in hospital patients. A considerable amount of intrinsic factor was present in gastric juice secreted in the absence of any stimulant, and this amount was normally far in excess of that required for the absorption of dietary vitamin $B_{12}$. Histamine and insulin were equally effective as stimulants of gastric-intrinsic-factor secretion, but carbachol did not produce an increase in secretion above the pre-injection level. The increased secretion of intrinsic factor following either histamine or insulin preceded the secretion of both acid and pepsin.

We wish to thank Professor W. T. Irvine both for his interest in the investigation and for permission to study his patients. We are indebted to Miss Valerie Berry for carrying out many of the intrinsicfactor assays and to $\mathrm{Mr}$. John Hall for the pepsin estimations.
ADDENDUM.-Since submitting this paper for publication, Jeffries, Benjamin, and Sleisenger (Clin. Res., 1964, 12, 209) have reported the effect of various pharmacological substances on the secretion of intrinsic factor. Their results using histamine are similar to those reported above.

\section{REFERENCES}

Abels, J., Bouma, W., and Nieweg, H. O. (1963). Biochim. biophys. Acta (Amst.), 71, 227.

Ardeman, S., and Chanarin, I. (1963). Lancet, 2, 1350.

Baker, S. J., and Mollin, D. L. (1955). Rev. Hémat., 10, 180.

Glass, G. B. J. (1963). Physiol. Rev., 43, 529.

Hunt, J. N. (1948). Biochem. f., 42, 104.

Jeffries, G. H., Sleisenger, M. H., and Benjamin, L. L. (1963). F. clin. Invest., 42, 442.

Kay, A. W. (1953). Brit. med. f., 2, 77.

Mollin, D. L., Booth, C. C., and Baker, S. J. (1957). Brit. F. Haemat., 3, 412 .

Sullivan, L. W., Herbert, V., and Castle, W. B. (1963). F. clin. Invest., 42, 1443.

\title{
Antibacterial Activity of Lincomycin and Pristinamycin : A Comparison with Erythromycin
}

\author{
MARY BARBER,* M.D. ; PAMELA M. WATERWORTH,*† F.I.M.L.T.
}

Brit. med. F., 1964, 2, 603-606

Lincomycin is an antibiotic isolated from a strain of Streptomyces lincolnensis in the Research Laboratories of the Upjohn Company, Michigan, in 1961 (Mason, Dietz, and Deboer, 1962). It is a monobasic compound and is obtained as the hydrochloride, in which form it is very readily soluble in water. The hydrochloride has the empirical formula $\mathrm{C}_{18} \mathrm{H}_{34} \mathrm{~N}_{2} \mathrm{O}_{6} \mathrm{~S}$. $\mathrm{HCl} \cdot \frac{1}{2} \mathrm{H}_{2} \mathrm{O}$ (molecular weight 452) (Herr and Bergy, 1962). Early reports indicate that it has an activity similar to that of erythromycin against Gram-positive cocci both in vitro and in experimental infections in mice (Lewis, Clapp, and Grady, 1962), although the high solubility and low molecular weight suggest that it is not a macrolide.

Pristinamycin (pyostacine) was isolated in the RhonePoulenc Research Laboratories in the nineteen-fifties from a strain of Streptomyces pristinae spiralis. A series of laboratory and clinical studies were published together in Semaine Thérapeutique (Benazet et al., 1962). It is a mixture of two antibiotics, and recent studies have shown that there is a broad chemical similarity between pristinamycin and a number of other antibiotic mixtures-namely, staphylomycin (de Somer and van Dijck, 1955 ; van Dijck, Vanderhaeghe, and de Somer, 1957), ostreogrycin (E 129, Glaxo) (see Garrod and Waterworth, 1956), streptogramin (Merck \& Co.) (Verwey, West, and Miller, 1958), synergistin (PA 144, Pfizer \& Co.) (Celmer, 1955-6 ; Hobbs and Celmer, 1959), and mikamycin (Arai, Fukahara, Nakamura, Yonehara, and Umezawa, 1958; Yamaguchi, 1961). Partial cross-resistance with erythromycin has been recorded in the case of ostreogrycin (Garrod and Waterworth, 1956) and streptogramin (Jones, Nichols, and Finland, 1956).

\section{Materials and Methods}

Lincomycin hydrochloride and pristinamycin were kindly supplied respectively by Upjohn Ltd. and May \& Baker Ltd.
Solutions of lincomycin were prepared in distilled water. Pristinamycin, however, is of very low solubility in water, and stock solutions ( $1 \mathrm{mg} . / \mathrm{ml}$.) were therefore prepared in alcohol. Bacteriostatic tests were carried out by preparing serial doubling dilutions of antibiotic in nutrient agar and inoculating with a standard 1-mm. loopful of an overnight broth culture, except where otherwise stated diluted 1 in 500 . Laked or heated blood was added for those bacteria requiring it.

\section{Bacteriostatic Activity}

The general spectrum of bacteriostatic activity of lincomycin and pristinamycin is shown in Table I. It will be seen that both compounds are highly active against Staph. aureus, Str. pyogenes, and Str. pneumoniae. Strains of Str. faecalis and $H$. influenzae were fairly highly sensitive to pristinamycin, but strains of both species were inhibited only by from 4-16 $\mu \mathrm{g}$. of lincomycin $/ \mathrm{ml}$. The strains of Neisseria tested were all highly sensitive to pristinamycin but resistant to lincomycin. All strains of Shigella, Salmonella, and Escherichia spp. were highly resistant to both antibiotics.

The 120 staphylococci referred to in Table I were a random selection of strains recently isolated in the routine hospital laboratory. The numbers resistant to various antibiotics were: penicillin 72 , streptomycin 40 , tetracycline 41 , erythromycin 17 , methicillin 3, and chloramphenicol 1. Further tests were carried out with a collection of 12 erythromycin-resistant strains of Staph. aureus which were typical representatives of one or other of the two resistant types described by Garrod (1957). The results are given in Table II. Seven of the strains showed double resistance to erythromycin and spiramycin, and three of these seven were also resistant to lincomycin. The remaining

* Department of Bacteriology, Postgraduate Medical School of London. +Working with a full-time grant from the Medical Research Council. 
five strains showed the dissociated type of resistance described by Garrod (1957); that is to say, they were resistant to erythromycin but sensitive to other macrolides-for example, spiramycin. All these five were sensitive to lincomycin. None of the 12 strains was resistant to pristinamycin.

\begin{tabular}{|c|c|c|c|c|}
\hline TABLE I. $-M$ & Minimum & Inhibitory & Concentration & $(\mu g . / m l)$. \\
\hline & & $\begin{array}{l}\text { No. of } \\
\text { Strains }\end{array}$ & Lincomycin & Pristinamycin \\
\hline $\begin{array}{l}\text { Staphylococcus aureus } \\
\text { Str. pyogenes } \\
\text { Str. pneumoniae } \\
\text { Streptococcus faecalis } \\
\text { Bacillus anthracis }\end{array}$ & $\begin{array}{l}\cdots \\
\cdots \\
\cdots \\
\cdots\end{array}$ & $\begin{array}{r}120 \\
14 \\
16 \\
14 \\
7\end{array}$ & $\begin{array}{c}0.5-2 \\
0.06-0.12 \\
0.06-0.5 \\
4-16 \\
0.25-0.5\end{array}$ & $\begin{array}{c}0.12-0.5 \\
0.06 \\
0.06-0.25 \\
0.5-2 \\
0.25-0.5\end{array}$ \\
\hline Neisseria gonorrhoeae: & $\because$ & $\begin{array}{r}6 \\
16\end{array}$ & & $\begin{array}{l}0.5 \\
0.25\end{array}$ \\
\hline $\begin{array}{l}\text { N. meningitidis... } \\
\text { N. catarrhalis } \\
\text { Haemophilus influenzae } \\
\text { Shigella flexneri } \\
\text { Sh. sonnei } \\
\text { Sh. shigae } \\
\text { Salmonella typhi } \\
\text { Salm. spp. } \\
\text { Escherichia coli }\end{array}$ & $\begin{array}{l}\because \\
\because \\
\because \\
\because \\
\because \\
\because \\
\because\end{array}$ & $\begin{array}{r}9 \\
2 \\
8 \\
14 \\
5 \\
2 \\
1 \\
7 \\
7 \\
16\end{array}$ & $\begin{array}{c}32 \\
>32 \\
16->32 \\
4-16 \\
128->128 \\
>128 \\
128 \\
>128 \\
>128 \\
>128\end{array}$ & $\begin{array}{c}0 \cdot 12-0 \cdot 5 \\
0 \cdot 06 \\
0 \cdot 06-0 \cdot 5 \\
0.5-4 \\
64-128 \\
128 \\
64 \\
128 \\
128 \\
32-128\end{array}$ \\
\hline
\end{tabular}

Table II.-Activity Against Erythromycin-resistant Strains of Staph.

\begin{tabular}{|c|c|c|c|c|}
\hline $\begin{array}{l}\text { No. of } \\
\text { Strains }\end{array}$ & Erythromycin & Spiramycin & Lincomycin & Pristinamycin \\
\hline $\begin{array}{l}3 \\
4 \\
5 \\
1 \text { (= sens. } \\
\quad \text { control) }\end{array}$ & $\begin{aligned} &> 32 \\
& 8 \\
& 8 \\
& 0 \cdot 12\end{aligned}$ & $\begin{array}{r}>128 \\
64 \\
8 \\
8\end{array}$ & $\begin{array}{c}>64 \\
0.5-1 \\
0.5-1 \\
0.5\end{array}$ & $\begin{array}{c}0.25-0.5 \\
0.1-0.25 \\
0.25 \\
0.25\end{array}$ \\
\hline
\end{tabular}

\section{Effect of Various Conditions on Bacteriostatic Activity}

pH.-Bacteriostatic tests were carried out with a strain of Staph. aureus in medium at $\mathrm{pH} 6.0,6.5,7.0,7.5,8.0$, and 8.5. The results are given in Table III. It will be seen that

TABLE III.-Effect of $\mathrm{pH}$ on Bacteriostatic Activity Against Staph. aureus. Figures Represent Minimum Inhibitory Concentrations $(\mu g . / m l$.

\begin{tabular}{c|c|c}
$p H$ & Lincomycin & Pristinamycin \\
\hline 6.0 & 8 & 0.25 \\
6.5 & 1 & 0.25 \\
7.0 & 1 & 0.25 \\
7.5 & 0.5 & 0.25 \\
8.0 & 0.5 & 0.25 \\
8.5 & 0.25 & 0.25
\end{tabular}

lincomycin, as is the case with the macrolides, is progressively less active as the $p \mathrm{H}$ falls, and at $p \mathrm{H} 6$ the activity is only oneeighth that in a neutral medium. Pristinamycin was unaffected by the $\mathrm{pH}$ within this range.

Inoculum Size.-Six strains of Staph. aureus were tested for sensitivity to lincomycin with the standard inoculum-that is, a loopful of 1 in 500 dilution of an overnight broth culture -and also with a loopful of undiluted culture. In no case was there more than a twofold increase in the minimum inhibitory concentration with the larger inoculum.

Serum.-A strain of Staph. aureus was tested in broth and in $90 \%$ human serum, in both cases with a diluted and undiluted inoculum. With lincomycin there was a twofold increase in the minimum inhibitory concentration in serum with the small inoculum and a fourfold increase with the large inoculum. With pristinamycin the respective increases were sixteenfold and thirty-twofold.

\section{Development of Resistance to Staph. aureus}

Erythromycin-sensitive Strains Passaged in Erythromycin.Eight strains were passaged 25 times in the presence of erythromycin. As appears in Table IV, all the strains showed a double increase in resistance to both erythromycin and spiramycin. With six strains the increase to erythromycin was 4,000 -fold or more; three of these strains showed a $500->$ 1,000 -fold increase in resistance to lincomycin, and the other three showed a slight increase in resistance to this antibiotic. All eight strains showed a slight or moderate increase in resistance to pristinamycin, and the degree of resistance was greatest with the strains showing the least increase to the other antibiotics.

TABLE IV.-Erythromycin-sensitive Strains of Staph. aureus. Effect of Passages in Erythromycin, Lincomycin, or Pristinamycin. Fold Increase in Resistance

A. Passaged in Erythromycin (25 transfers)

\begin{tabular}{c|c|c|c|c}
\hline No. of Strains & Erythromycin & Spiramycin & Lincomycin & Pristinamycin \\
\cline { 2 - 5 } & $4,000-8,000$ & $>256$ & $500->1,000$ & $2-4$ \\
3 & $4,000-8,000$ & $>256$ & $2-16$ & $2-8$ \\
1 & 1,000 & 64 & 2 & 8 \\
1 & 64 & 32 & 0 & 16
\end{tabular}

B. Passaged in Lincomycin (32 transfers)

\begin{tabular}{c|c|c|c|c}
\hline No. of Strains & Lincomycin & Pristinamycin & Erythromycin & Spiramycin \\
\cline { 2 - 4 } & $>256$ & 0 & $>1,000$ & $>128$ \\
1 & 2 & 2 & 0 & 0 \\
3 & 0 & 0 & 0 & 0 \\
\hline
\end{tabular}

C. Passaged in Pristinamycin (32 transfers)

\begin{tabular}{c|c|c|c|c}
\hline No. of Strains & Pristinamycin & Lincomycin & Erythromycin & Spiramycin \\
\cline { 2 - 4 } & 256 & $2-32$ & $32-64$ & $2-8$ \\
2 & 64 & 8 & $8-128$ & $2-16$ \\
1 & 8 & 2 & 8 & 2 \\
\hline
\end{tabular}

Erythromycin-sensitive Strains Passaged in Lincomycin and Pristinamycin.-Five strains were passaged 32 times in media containing lincomycin and pristinamycin separately. The results are given in Table IV. After passage in lincomycin, one strain showed a gross increase in resistance to lincomycin, erythromycin, and spiramycin, but not to pristinamycin. No significant change was noted with the other four strains. After passage in pristinamycin, all the strains showed an increase in resistance to this antibiotic, ranging from an 8 to 256-fold difference, and all strains showed some increase in resistance to. the other three antibiotics.

Strains Showing Dissociated Erythromycin Resistance.-Four strains resistant to erythromycin but sensitive to spiramycin and also to lincomycin and pristinamycin were passaged 25 times in the presence of erythromycin and one such strain 32 times separately in the presence of lincomycin and pristinamycin. The results are given in Table V. After passage in erythromycin all the strains showed a gross increase in resistance to this antibiotic but not to spiramycin or either of the other two antibiotics. The strain passaged in lincomycin showed a moderate increase in resistance to lincomycin and pristinamycin but no significant change with erythromycin and spiramycin. Passage of the same strain in pristinamycin appeared to increase its resistance to erythromycin and spira-

TABLE V.-Strains of Staph. aureus Showing Dissociated Erythromycinresistance. Effect of Passage in Erythromycin, Lincomycin, or Pristinamycin. Fold Increase in Resistance

A. Passaged in Erythromycin (25 transfers)

\begin{tabular}{c|c|c|c|c}
\hline No. of Strains & Erythromycin & Spiramycin & Lincomycin & Pristinamycin \\
\hline 4 & 256 & 2 & $0-2$ & $0-2$
\end{tabular}

B. Passaged in Lincomycin ( 32 transfers)

\begin{tabular}{c|c|c|c|c}
\hline No. of Strains & Lincomycin & Pristinamycin & Erythromycin & Spiramycin \\
\hline 1 & 8 & 16 & -2 & 0
\end{tabular}

C. Passaged in Pristinamycin (32 transfers) \begin{tabular}{c|c|c|c|c}
\hline No. of Strains & .Pristinamycin & Lincomycin & Erythromycin & Spiramycin \\
\hline 1 & 2 & 64 & 16
\end{tabular} 
mycin, but the strain remained sensitive to pristinamycin and lincomycin.

\section{Effect of Presence of Erythromycin on Resistance to Lincomycin and Pristinamycin of a Strain of the Dissociated Resistant Type}

Garrod (1957) showed that strains of Staph. aureus which were resistant to erythromycin but sensitive to other macrolides appeared resistant to the latter in the presence of erythromycin. In view of the cross-resistance noted in the above studies between lincomycin, and to a less extent pristinamycin, and the macrolides, it was thought worth while to try this test with these antibiotics. For this purpose one of the strains of Staph. aureus which were resistant to erythromycin but sensitive to other macrolides was tested for sensitivity to lincomycin and pristinamycin in the presence of various concentrations of erythromycin. The results are shown in Table VI, from which it will be seen that the presence of erythromycin rendered the strain resistant to lincomycin but not to pristinamycin.

Further tests of the effect of erythromycin on rendering staphylococci of this type resistant to other antibiotics were carried out by flooding plates with an overnight broth culture of the staphylococcus and placing on the surface three blottingpaper strips soaked respectively in erythromycin, spiramycin, and lincomycin, the two latter being placed at right angles to the former, as shown in the accompanying Figure. By this means erythromycin was shown to render strains of the dissociated resistant type resistant also to lincomycin and spira-

TABLE VI.-Effect of Presence of Erythromycin on Sensitivity of Strains of Staph. aureus, Showing Dissociated Resistance to Erythromycin

\begin{tabular}{c|c|c}
\hline $\begin{array}{c}\text { Concentration of } \\
\text { Erythromycin }(\mu \mathrm{g} . / \mathrm{ml} .)\end{array}$ & \multicolumn{2}{|c}{ Minimum Inhibitory Concentration ( $\mu \mathrm{g} . / \mathrm{ml})}$. \\
\cline { 2 - 3 } & Lincomycin & Pristinamycin \\
\hline 0 & 1 & 0.25 \\
0.25 & 64 & 0.25 \\
1.0 & $>64$ & 0.25 \\
4 & & 0.5 \\
\hline
\end{tabular}

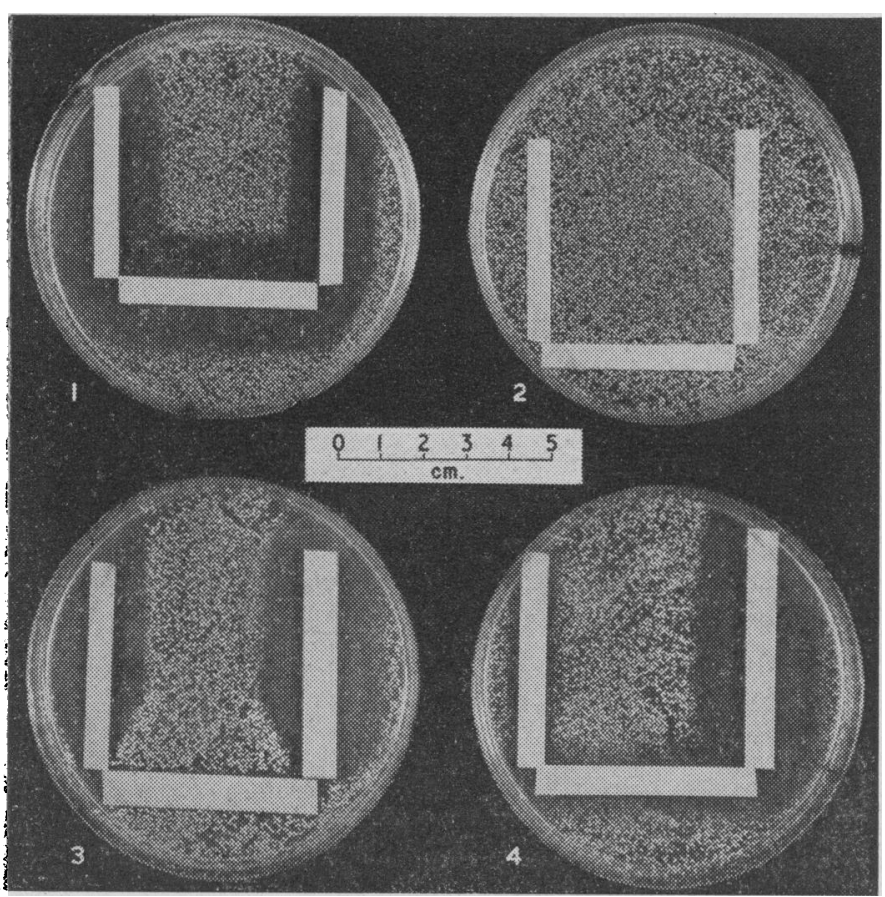

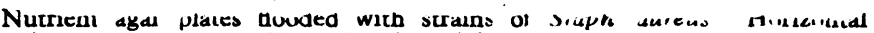
strip: erythromycin. Verucal strips : left, spiramycin; right. lincomycin. 1: Erythromycin-sensitive strain. 2: Strain showing double resistance to erythromyin and spiramycin and also resistance to lincomvcin 3. Surain showing dissociated ervibromycin resistance. Note reststunce to both spiramycin and lincomyctn at iunction with erythromyctn. 4: Strain showing double resistance to eryinruinycin and spiramycin but sensiuve to lincomycin. mycin (see Fig.). Control tests carried out with the unrelated antibiotics novobiocin, chloramphenicol, methicillin, fucidin, kanamycin, and vancomycin did not show this phenomenon.

\section{Discussion}

It is clear from these studies that lincomycin resembles the macrolides in antibacterial activity in spite of its chemical dissimilarity. Not only is the antibacterial spectrum of lincomycin similar to that of erythromycin, except that the latter shows much higher activity against the Neisseriae strains, but at least with staphylococci there is evidence of cross-resistance.

As shown by Garrod (1957), cross-resistance among the macrolide antibiutics is complex. When staphylococci are habituated to one of the macrolides by passage in vitro they show complete cross-resistance with the other macrolides. This Garrod (1957) termed "double resistance." Erythromycinresistant strains isolated from patients in some cases show this double type of resistance, but in other instances they show a dissociated type of resistance-that is, they are resistant to erythromycin but sensitive to spiramycin and oleandomycin. Strains of this type were found by Garrod (1957) to consist of a heterogeneous population of cells, less than $1 \%$ of which showed the highest degree of resistance to erythromycin. Further studies in which erythromycin was added to the cultures at various intervals after incubation showed that, in fact, the strains were resistant to erythromycin only when grown in its presence. Thus the resistance was conditioned by the presence of the antibiotic. Finally it was shown that strains of this type became resistant to the other macrolides in the presence of erythromycin.

In our investigation, strains showing double resistance to erythromycin and spiramycin, whether isolated from patients or by passage of sensitive strains in erythromycin in vitro, frequently, although not invariably, showed an associated gross increase in resistance to lincomycin. Of five sensitive strains passaged in lincomycin in vitro, only one showed a gross increase in resistance to this antibiotic, but this strain had a similar increase in resistance to erythromycin and spiramycin.

On the other hand, all the strains showing the dissociated type of resistance to erythromycin appeared to be fully sensitive to lincomycin in the usual type of test, but in the presence of erythromycin were rendered resistant to lincomycin as they were also to spiramycin. This has come to be regarded as a test of identity as a macrolide (Waterworth, 1960), and a positive result with the chemically unrelated antibiotic, lincomycin, was something of a surprise. However, lincomycin does show cross-resistance with the erythromycin group, and the test was negative with all the other unrelated antibiotics tested.

Passage of strains of the dissociated-resistant type in erythromycin increased their resistance to this antibiotic but did not change the character of the resistance, so that in the absence of erythromycin they remained sensitive to spiramycin and also to lincomycin. This is an important finding and will have to be taken into account in any attempt to explain how these two types of resistance to erythromycin arise naturally.

The results here recorded with pristinamycin are in keeping with its chemical similarity to ostreogrvcin. As with the latter antibiotic (see Garrod and Waterworth, 1957), there is some cross-resistance with the macrolides, but it is of a low order. Three of five strains habituated to pristinamycin showed a moderate increase in resistance to lincomycin, but the only strain rendered resistant to lincomycin by passage in that antibiotic remained fully sensitive to pristinamycin.

\section{Summary}

The antibacterial activity of lincomycin and pristinamycin has been studied and compared with that of erythromycin. 
In spite of chemical differences, lincomycin has been shown to have an antibacterial activity similar to that of the macrolides, including partial cross-resistance.

Pristinamycin has an activity that might have been predicted from its chemical similarity to ostreogrycin.

\section{REFERENCES}

Arai, M., Fukahara, S., Nakamura, S., Yonehara, H., and Umezawa, H. (1958). F. Antibiot. (Tokyo), Ser. A, 11, 14.

Benazet, F., and numerous others (1962). Sem. thér., 38, 13, 19, 25, 49, $57,68,71$

Celmer, W. D. (1955-6). Antibiot. Ann., p. 452. de Somer, P., and van Dijck, P. (1955). Antibiot. and Chemother., 5, 632

Garrod, L. P. (1957). Brit. med. 7., 2, 57.

and Waterworth, P. M. (1956). Ibid., 2, 61.

Herr, R. R., and Bergy, M. E. (1962). Antimicrobial Ag. Chemother., p. 560 .

Hobbs, D. C., and Celmer, W. D. (1959). Fed. Proc., 18, 246.

Jones, W. F., Nichols, R. L., and Finland, M. (1956). Proc. Soc. exp. Biol. (N.Y.), 93, 388.

Lewis, C. Clapp, H. W., and Grady, J. E. (1962). Antimicrobial Ag. Chemother., p. 570.

Mason, D. J., Dietz, A., and Deboer, C. (1962). Ibid., p. 554.

van Dick, P., Vanderhaeghe, H., and de Somer, P. (1957). Antibiot. and Chemother., 7, 625 .

Verwey, W. F., West, M. K., and Miller, A. K. (1958). Ibid., 8, 500.

Waterworth, P. M. (1950). Antibiot. and Chemother., 10, 101.

Yamaguchi, H. (1961). F. Antibiot. (Tokyo), Ser. A, 14, 313.

\title{
Identification of Histamine Metabolite 1-methyl,4-imidazole Acetic Acid in Human Urine and its Absence in Status Asthmaticus
}

\author{
JAMES W. KERR,* M.B., M.R.C.P., M.R.C.P.G
}

Brit. med. F., 1964, 2, 606-608

Since the identification of histamine by Barger \& Dale (1910) and the appreciation of its pharmacological activity (Dale and Laidlaw, 1911) there has been abundant evidence that histamine release is concerned in the reactions of hypersensitivity. The introduction of antihistamine drugs (Halpern, 1942) and the demonstration of their value in the treatment of hay-fever and urticaria appeared to confirm the part played by histamine release in these conditions. In sharp contrast is their ineffectiveness in the treatment of bronchial asthma.

The evidence that histamine metabolism is disturbed in an attack of bronchial asthma is conflicting and confused. Rose, Rusted, and Fownes (1950) measured histamine levels in arterial and pulmonary mixed venous blood of asthmatic patients during an induced attack of asthma. They reported arterial levels of free histamine higher than the pulmonary. mixed venous levels during the attack. Both were higher than in non-asthmatic control patients. Human bronchial rings from a case of grasspollen asthma have been shown to constrict when challenged with pollen antigen, with the liberation of histamine into the organ bath (Schild, Hawkins, Mongar, and Herxheimer, 1951). On the other hand, Mitchell, Logan, Peters, and Henderson.(1954), in a careful study of asthmatic children, showed that in intervals between attacks the free-histamine output in the urine was within the normal range and during acute attacks of asthma the concentration of free histamine in the urine tended to decrease.

Karjala, Turnquest, and Schayer (1956), Schayer and Karjala (1956), and Shayer (1959) have studied the metabolism of physiological quantities of injected ${ }^{14} \mathrm{C}$ ring labelled histamine in animals and man. Methylation of the imidazole ring $\mathrm{N}$ is a major route of metabolism (Fig. 1). The methyl histamine formed * Senior Medical Registrar, Medical Research Council
Atheroma Research Unit, Western Infirmary, Glasgow. is biologically much less active than histamine and is largely oxidized to 1-methyl,4-imidazole acetic acid (Schayer and Karjala, 1956). When minute amounts of ring labelled ${ }^{14} \mathrm{C}$ histamine are injected intradermally in man, over $80 \%$ of the radioactivity can be recovered in the urine within six hours. Urine analysis shows that 1-methyl,4-imidazole acetic acid is
FIG. 1.-Histamine is formed by the decarboxylation of L-histidine, and 1-methyl,4-imidazole acetic acid is a specific metabolite of histamine metabolism. The riboside of imidazole acetic acid can be formed by the transamination of $\mathrm{L}$-histidine or via histamine.

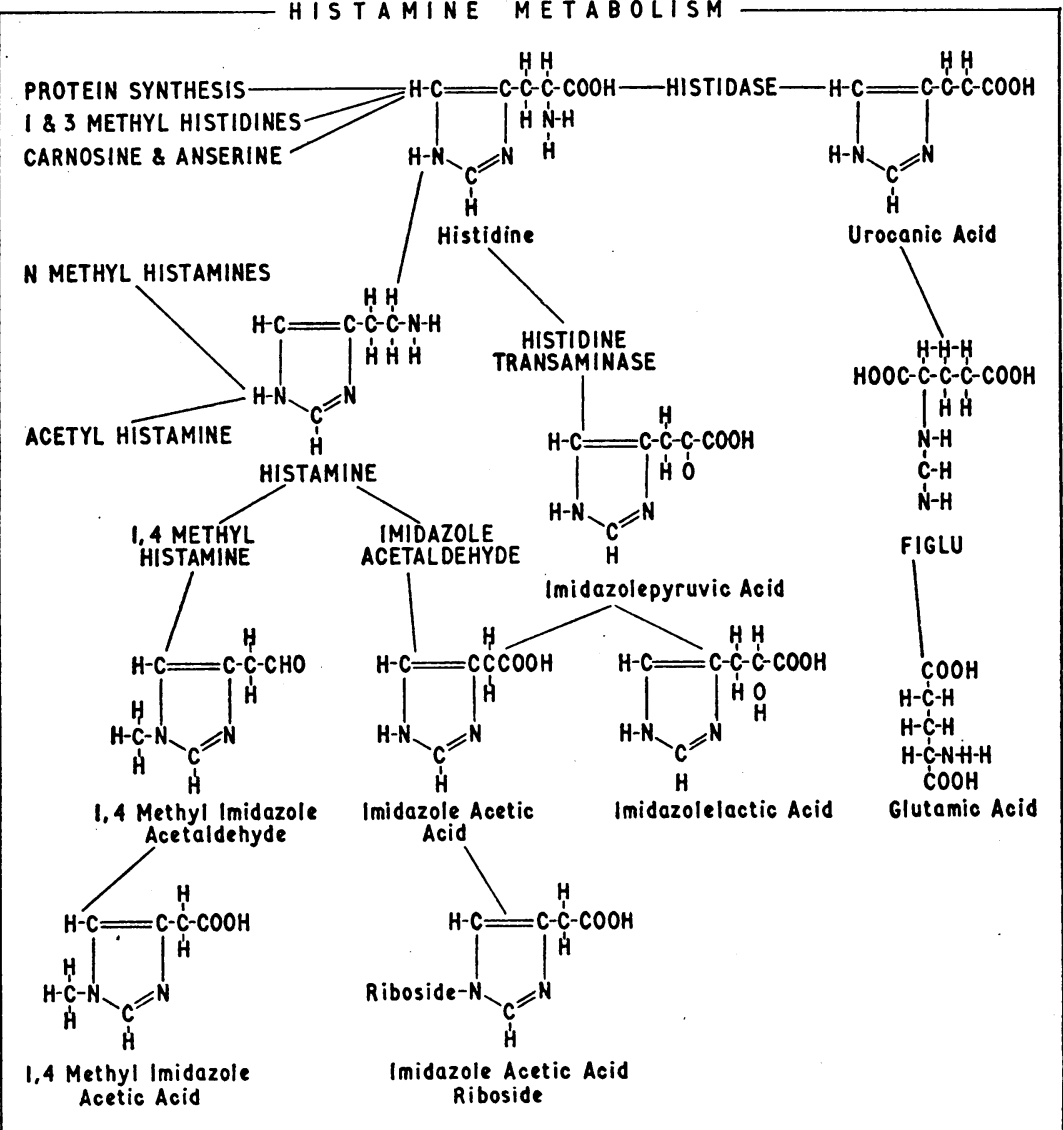

